\title{
Efficacy of Brassicaceous Seed Meal Formulations for the Control of Apple Replant Disease in Conventional and Organic Production Systems
}

\author{
Mark Mazzola, USDA Agricultural Research Service, Tree Fruit Research Laboratory, 1104 N. Western Avenue, \\ Wenatchee, WA 98801; and Jack Brown, Department of Plant, Soil and Entomological Sciences, University of \\ Idaho, Moscow 83844-2339
}

\begin{abstract}
Mazzola, M., and Brown, J. 2010. Efficacy of brassicaceous seed meal formulations for the control of apple replant disease in conventional and organic production systems. Plant Dis. 94:835-842.

The efficacy of brassicaceous seed meals for the control of apple replant disease and the effects of such treatments on the causal pathogen complex were examined in conventional and organic production systems. When used in conjunction with a postplant application of mefenoxam, Brassica juncea and Sinapis alba seed meal soil amendments were as effective as preplant fumigation of soil with 1,3-dichloropropene-chloropicrin in terms of disease control, tree growth, and overall fruit yields of Gala/M26. Brassica napus seed meal amendment-mefenoxam soil drench also enhanced yields in a manner comparable to preplant fumigation, but vegetative growth was intermediate between the control and fumigation treatments. When applied alone, seed meal amendments failed to enhance tree growth or control disease to the level attained in response to soil fumigation. Postplant mefenoxam treatments revealed that failure of seed meal amendments to enhance tree growth and yield when used independently was due, at least in part, to increased apple root infection by Pythium spp. in B. napus and $S$. alba seed meal-amended soils, and by Phytophthora cambivora in B. juncea-amended soil. As mefenoxam treatment is not compatible with organic cropping systems, a seed meal blend was formulated which, based upon biological activity, was predicted to suppress known components of the target pathogen complex without need of additional treatment. Gala/M26 trees planted in soils treated with a 1:1 ratio of $B$. juncea:B. napus seed meal blend performed as well in terms of disease control and vegetative growth as trees cultivated in fumigated soil at an organic-certified orchard. Because these trials utilized the highly susceptible rootstock M26, the results demonstrate that these amendments are a viable alternative to soil fumigation for the control of apple replant disease in both conventional and organic systems.
\end{abstract}

Preplant soil fumigation has been the standard treatment for the control of perennial crop replant diseases, including apple replant disease $(8,10)$. Although significant effort has been invested in the development of alternatives to soil fumigation for control of replant diseases $(5,21-$ 23,26-28,30,31), there continues to be a lack of effective and economically feasible nonfumigant control strategies. Confusion regarding the etiology of replant diseases has been a significant impediment in the design of alternative control methods, and this uncertainty can be attributed to the diversity of components in an orchard ecosystem that can ultimately depress tree growth in new plantings established on old orchard sites (26). However, despite the potential of multiple factors to influence

Corresponding author: M. Mazzola

E-mail: mark.mazzola@ars.usda.gov

Accepted for publication 26 March 2010.

doi:10.1094/PDIS-94-7-0835

This article is in the public domain and not copyrightable. It may be freely reprinted with customary crediting of the source. The American Phytopathological Society, 2010. replant disease severity, repeated reports demonstrating dramatic improvement in tree growth and fruit yield in response to soil pasteurization $(9,14)$ or fumigation $(8,10,19,23)$ prior to replanting old orchard sites offer evidence that replant disease is primarily a biological phenomenon rather than the direct result of abiotic factors.

The etiology of apple replant disease is commonly characterized as a pathogen complex varying from site to site, even among orchards within close proximity (26). In contrast, studies conducted in Washington State indicated that the pathogen complex was somewhat consistent among orchard sites and that the primary agents included fungi/oomycetes of the genera Rhizoctonia, Cylindrocarpon, and Pythium, along with Phytophthora cactorum, at times acting in concert with the lesion nematode, Pratylenchus penetrans $(14,19)$. Subsequent studies have decisively supported original findings documenting a causal pathogen complex (19). Regardless of the apparent regularity in pathogen composition, the development of targeted approaches for the management of a disease syndrome incited by such a diverse biological consortium seems improbable; however, progress has been at- tained in achieving this goal in conventional production systems. For instance, on sites lacking significant lesion nematode numbers, preplant Brassica napus seed meal soil amendment used in conjunction with a postplant application of mefenoxam provided effective disease control and enhanced fruit yields, at times to levels similar to those attained in response to soil fumigation (19). Mefenoxam application is a necessary component of this management strategy due to the stimulatory effect of the amendment on resident populations of Pythium spp. $(16,19)$. In the instance where lesion nematode was a significant component of the pathogen complex, the seed meal-mefenoxam treatment enhanced tree growth relative to the nontreated control, but was inferior to preplant soil fumigation primarily due to ineffective suppression of Pratylenchus penetrans (19).

The need for a postplant mefenoxam soil drench diminishes or negates the utility of $B$. napus seed meal amendment as a disease control option in organic production systems. In addition, widespread adoption of such a disease control strategy will require further demonstration of consistent efficacy, particularly across soil systems where the lesion nematode contributes to disease development. Brassicaceous seed meal soil amendments provide disease control through various mechanisms, both biological and chemical, which vary with both the seed meal source and the target pathogen $(6,16)$. Although products resulting from the hydrolysis of 3-butenyl glucosinolate, the dominant glucosinolate found in B. napus seed meal utilized in the previous studies, are not capable of suppressing Pythium spp. (12), alternative seed meals exist which do not elicit a stimulatory effect on Pythium populations resident to orchard soils (17).

Individual and composite seed meal formulations were evaluated in greenhouse and growth chamber assays for the capacity to suppress the diverse components of the pathogen complex inciting apple replant disease (16). In the current study, brassicaceous seed meals possessing dissimilar mechanisms of biological activity were evaluated in field trials with or without a postplant mefenoxam soil drench to assess their potential to serve as an effective nonfumigant alternative for the management of apple replant disease. Based 
upon the initial findings from this study in a conventional orchard and the spectrum of pathogen suppression obtained with the various seed meals, a seed meal formulation was devised and evaluated for use in an organic orchard production system.

\section{MATERIALS AND METHODS}

Orchard sites. Studies were conducted at the Columbia View Research (CV) orchard near Orondo, WA and at a commercial certified-organic orchard (Stormy Mountain Ranch [SMR]) near Chelan, WA. Apple (Malus domestica Borkh.) cv. Red Delicious on seedling rootstock and cv. Jonagold on M26 rootstock were previously planted at the CV and SMR orchards, respectively. Removal of the old orchard blocks was conducted in 2000 and 2004 at the SMR and CV orchard, respectively. The biological elements contributing to disease development at the $\mathrm{CV}$ orchard have been described (13-15) and include $R$. solani AG-5 and AG-6, Pythium heterothallicum, $P$. intermedium, $P$. recalcitrans (20), Phytophthora cactorum, and Cylindrocarpon destructans. A similar biological complex is present in SMR orchard soils, although species composition of the Pythium and Rhizoctonia populations were determined in this study as described below. Although lesion nematode numbers were consistently low in CV orchard soil $(14,19)$, plant bioassays conducted prior to establishment of the field trials predicted a moderately high lesion nematode pressure at the SMR orchard. Pratylenchus penetrans was recovered from Gala seedlings planted in SMR orchard soil at densities of 150 to $200 \mathrm{~g}^{-1}$ root.

Brassicaceous seed meals. Seed meals utilized in these studies include Brassica napus cv. Athena (3), B. juncea cv. Pacific Gold (2), and Sinapis alba cv. IdaGold (1). Mineral and glucosinolate content of these seed meals were previously determined and published (17). IdaGold and Pacific Gold seed meal contained over ninefold and almost 12-fold higher total glucosinolate content, respectively, compared to the low glucosinolate Athena meal. The primary glucosinolate in Pacific Gold is allyl, accounting for over $99 \%$ of the total $302.9 \mu \mathrm{mol} \mathrm{g} \mathrm{g}^{-1}$ of glucosinolate in the defatted seed meal. Similarly, the primary glucosinolate type in IdaGold is 4hydroxybenzyl glucosinolate, accounting for over $96 \%$ of the total content. All three cultivars produce low concentrations of 2hydrox-3-butenyl glucosinolate, and the major glucosinolate types in Athena are 3butenyl and 4-pentenyl glucosinolate. Allyl glucosinolate is only present in Pacific Gold seed meal, while 4-hydroxybenzyl glucosinolate is found only in IdaGold seed meal.

Among these seed meals, only that from B. juncea yields a volatile isothiocyanate when incorporated into soil. Seed meal from $B$. juncea, but not B. napus or $S$. alba, can suppress Pythium and provides superior suppression of both Pratylenchus penetrans (17) and C. destructans (M. Mazzola, unpublished data). All three seed meals effectively suppress apple root rot incited by $R$. solani AG-5 and do so via both biological and chemical mechanisms (16).

Prior to mechanical seed crushing, the seed was heated to $50^{\circ} \mathrm{C}$, and during the crush process the seed meal reached temperatures no higher than $70^{\circ} \mathrm{C}$. The temperature attained by the seed meal in the oil extraction process was not high enough to cause degradation of glucosinolates or myrosinase. After this relatively low temperature crush, oil content of the seed was 10 to $11 \%$ of total weight. Seed meals were stored in waterproof metal storage bins until used to amend soil in this study.

CV orchard trial. Each treatment plot was $10.7 \mathrm{~m}$ in length and $2 \mathrm{~m}$ in width. Preplant soil fumigation with 1,3-dichloropropene-chloropicrin (Telone-C17; DowElanco, Indianapolis, IN) at a rate of 282 liters $\mathrm{ha}^{-1}$ was applied to five plots on 6 October 2004 by a commercial applicator. Seed meals in this, and all trials described below, were applied individually at a rate of $4.46 \mathrm{~kg} \mathrm{~m}^{-1}$ of tree row. Prior to application of seed meals, all plots were rotovated to a depth of $20 \mathrm{~cm}$ on 13 April 2005 . Amendments were applied to 10 separate plots per seed meal type on 14 April 2005, and plots were rotovated once more after application of treatments to incorporate seed meals to a depth of 15 to $20 \mathrm{~cm}$. For soils treated with $B$. juncea seed meal, clear plastic, 152- $\mu$ m-thick sheeting (Sunbelt Plastics, Monroe, LA) was placed over the plots immediately after rotovation to enhance soil retention of the biologically active volatile allyl isothiocyanate. Plastic sheeting was removed from the plots after 1 week. The site was planted to Gala/M26 apple on 19 May 2005. For the untreated and seed meal amended plots, a postplant mefenoxam (Ridomil Gold EC; Syngenta, Greensboro, NC) soil drench was applied to 5 of 10 plots for each soil treatment on 24 May 2005. Trees were grown under irrigation using standard orchard practices, including the maintenance of a weed-free under-tree strip (approximately $1.5 \mathrm{~m}$ wide) through intermittent use of glyphosate herbicide. Due to the approximately $6 \% \mathrm{~N}$ content of seed meals used, only nontreated and fumigated control plots were fertilized in 2005 with ammonium nitrate (30-0-0) at a rate of $112 \mathrm{~kg}$ $\mathrm{ha}^{-1}$ and in 2006 with urea (46-0-0) at a rate of $84 \mathrm{~kg} \mathrm{ha}^{-1}$. Thereafter, all plots were fertilized annually in the autumn with urea. The trial was designed as a randomized complete block consisting of five replicates per treatment with 10 trees per plot.

SMR orchard trials. Based upon the preliminary results obtained at the $\mathrm{CV}$ orchard trial reported here, it was apparent that none of the seed meals, when used alone, would effectively control replant disease. In addition, mefenoxam is not compatible with organic production, and thus it was apparent that none of the treatments employed at the $\mathrm{CV}$ orchard would be suitable for use in organic orchards. Therefore, a seed meal formulation was devised, based upon the biological activity spectrum of its individual components, with potential to circumvent the need for postplant application of mefenoxam. The seed meal formulation consisted of a 1:1 blend of B. napus cv. Athena and B. juncea cv. Pacific Gold seed meal. The initial experiment conducted at the SMR orchard was a rootstock trial which employed the apple rootstock M26. Treatments included a no treatment control, 1,3-dichloropropene-chloropicrin soil fumigation, $B$. napus seed meal amendment, and the $B$. napus:B. juncea seed meal blend amendment. The trial utilized a randomized complete block design consisting of three replicates with four trees in each plot. Soil fumigation was conducted in October 2005 , seed meal was applied on 3 May 2006 , the site was planted with $1.25-\mathrm{cm}$ diameter M26 rootstocks on 30 May 2006, and all trees were harvested on 11 October 2006.

The second trial, which involved establishment of a new orchard block at the SMR orchard, was initiated in 2007 and included a no treatment control, 1,3-dichloropropene-choloropicrin preplant soil fumigation, and soil amendment using the composite seed meal blend evaluated in the 2006 rootstock trial. The study utilized a randomized complete block design with six replicate plots and 12 trees per replicate for each treatment. Soil fumigation was conducted by the commercial applicator on 3 April, seed meal was applied on 23 April, and plots were covered with plastic sheeting as described above. Plastic was removed on 17 May, and the site was planted to Gala/M26 apple on 23 May 2007. The site was managed by the commercial grower using standard organic methods in fertility, pest and disease control, including cultivation of the tree row for weed management. As this was a commercial orchard operation, these newly established trees were not allowed to set fruit during the trial period, and thus yield data were not obtained.

Assessment of plant growth and yield. The effect of soil treatments on tree growth was assessed by monitoring the increase in tree diameter for the duration of each trial. The main stem of each tree was marked with latex paint at a point $0.7 \mathrm{~m}$ above the soil line, and diameter measurements were periodically conducted at this point using an electronic caliper at two perpendicular directions to achieve a mean trunk diameter. Fruit yield data were obtained each year at the $\mathrm{CV}$ orchard trial. Fruit were harvested from all trees, and all yield and 
growth data were recorded in the field on a per tree basis. All growth and yield data were combined on a per plot basis prior to statistical analysis.

Soil sampling and assessment of $P y$ thium spp. density. For each trial, a soil sample was collected from each plot on the date of planting, prior to mefenoxam application at the CV orchard, and at the end of the initial growing season. Soils were collected at two locations in each plot at a depth of 10 to $30 \mathrm{~cm}$. Soils were immediately transported to the laboratory for determination of Pythium populations as this pathogen, along with Pratylenchus penetrans, was perceived to be the dominant limitation for successful broad-scale use of individual brassicaceous seed meals for replant disease control. For each sample, 5 $\mathrm{g}$ of soil was suspended in $25 \mathrm{ml}$ of sterile distilled $\mathrm{H}_{2} \mathrm{O}$, vortexed for $90 \mathrm{~s}$, and serial dilutions of the suspension were plated onto a Pythium semiselective medium (PSSM; 18). Plates were incubated at room temperature and examined after 24 and 48 $\mathrm{h}$ to estimate soil populations of Pythium spp. Any emerging colonies of questionable morphology were examined microscopically to determine identity.

Root collection and microbial analysis. Root sampling was conducted during October of the initial growing season for each trial. In addition, root samples were collected in 2009 at the end of the third and fifth growing season for the SMR orchard trial established in 2007 and the CV orchard trial established in 2005, respectively. In the SMR orchard rootstock trial, all trees were harvested and root populations of Pratylenchus penetrans were determined for each plant. For the Gala/M26 CV and SMR orchard trials, root samples were collected from two trees in each treatment plot; the upper $5 \mathrm{~cm}$ of the soil surface was removed with a shovel and roots were collected at a depth of 5 to $20 \mathrm{~cm}$ at two opposing sides of the tree at a distance 20 to $40 \mathrm{~cm}$ from the tree base. A 0.5 -g tissue subsample from each tree was utilized for determination of $P$. penetrans root populations. Individual samples were placed into $125-\mathrm{ml}$ flasks containing $80 \mathrm{ml}$ of sterile distilled water. Flasks were placed on a reciprocal shaker at $150 \mathrm{rpm}$ and incubated at $22^{\circ} \mathrm{C}$ for 5 days. Nematodes were collected by passing the suspension twice through a 350-mesh sieve and backwashing into a counting dish. $P$. penetrans were counted using a light microscope $(\times 40)$.

A determination of apple root infection by oomycetes and fungi, including Cylindrocarpon, Rhizoctonia, and Pythium, was conducted by plating root segments ( 0.5 to $1.0 \mathrm{~cm}$ in length) on water agar amended with ampicillin $\left(100 \mu \mathrm{g} \mathrm{ml}^{-1}\right)$ and PSSM agar, as described previously (14). For SMR orchard samples, hyphal growth emanating from apple root segments representative of Pythium or Rhizoctonia spp. were subcultured onto fresh PSSM agar and water agar amended with ampicillin $\left(100 \mu \mathrm{g} \mathrm{ml}^{-1}\right)$, respectively, and incubated in the dark at $22^{\circ} \mathrm{C}$. After $72 \mathrm{~h}$, fungi were subcultured individually in $5 \mathrm{ml}$ of potato dextrose broth amended with ampicillin and grown without aeration for $96 \mathrm{~h}$. Mycelium was harvested and DNA was extracted using a MoBIO Ultraclean Microbial DNA isolation kit (MO BIO Labs, Carlsbad, CA). Polymerase chain reaction amplification of DNA was conducted using the internal transcribed spacer ITS4 and ITS5 primer set (29) as previously described (25). Amplification products were cloned into pCR 4-TOPO and transformed into chemically competent Escherichia coli TOP10 cells (Invitrogen, Carlsbad, CA). Plasmid DNA was extracted from transformants using the S.N.A.P. miniprep plasmid purification kit (Invitrogen), and inserts were sequenced using a Dye Terminator Cycle Sequencing Quick Start Kit (Beckman Coulter, Fullerton, CA) and a CEQ 8000 Genetic Analysis system (Beckman Coulter). Sequencing was conducted in one direction using the M13 reverse primer (5'-CAGGAAACA GCTATGAC-3'), and consistently yielded reads that were greater than $600 \mathrm{bp}$ in length. For each resulting sequence, a BLAST search was performed on GenBank to identify the most closely related species and anastomosis groups of $P y$ thium and Rhizoctonia, respectively.

Initial vegetative tree growth data established the need for additional examination of the spectrum of oomycetes colonizing apple roots at the $\mathrm{CV}$ orchard, and DNAbased protocols were utilized in these analyses. For each treatment, fine roots from one tree in each plot were collected on 9 October 2005 and immediately transported to the laboratory. DNA was extracted from a 50-mg fine root sample from each tree using the MO BIO UltraClean Plant DNA isolation kit (MO BIO Labs). The ITS2 region was targeted in polymerase chain reaction amplifications using the primers OOM-UP5.8S01 (5'CAACTTTCAGCAGTGGATGTCT-3'; 11) and Oom-lo28S-345H (5'-ACTTGTTCG CTATCGGTCTCGCA-3'; 24). Reactions were carried out in a volume of $50 \mu \mathrm{l}$ that included $1 \mu \mathrm{l}$ of diluted DNA ( 5 to $10 \mathrm{ng}$ ), 2.5 units of Amplitaq Gold DNA polymerase (Applied Biosystems, Foster City, CA), 1× manufacturer's reaction buffer, 3 $\mu \mathrm{l}$ of a $25-\mathrm{mM} \mathrm{MgCl}_{2}$ solution, and 200 $\mu \mathrm{M}$ each $\mathrm{dNTP}$. The cycling conditions were $94^{\circ} \mathrm{C}$ for $2 \mathrm{~min}$, followed by $30 \mathrm{cy}$ cles of $94^{\circ} \mathrm{C}$ for $60 \mathrm{~s}, 55^{\circ} \mathrm{C}$ for $45 \mathrm{~s}$, and $72^{\circ} \mathrm{C}$ for $60 \mathrm{~s}$, followed by 1 cycle at $72^{\circ} \mathrm{C}$ for $7 \mathrm{~min}$. Amplification products were cloned, sequenced, and analyzed as described above.

Data analysis. Data were analyzed using SigmaStat (version 3.1; Systat Software Inc., Point Richmond, CA). Growth and yield data for all trees in an individual plot were combined to attain a single value for use in analysis. Percent root infection data and soil population data were transformed to arcsine square root and $\log 10$ values, respectively. Data were subjected to analysis of variance, and means separation was performed using the StudentNewman-Keuls method.

\section{RESULTS}

CV orchard trial 2005 to 2009. Growth and yield of Gala/M26 apple at the CV orchard was significantly different among soil treatments. Mean tree diameter at planting was $13 \mathrm{~mm}$ at a height $0.7 \mathrm{~m}$ above ground level. Telone-C17 preplant soil fumigation and all seed meal treatments when used in conjunction with a postplant mefenoxam soil drench significantly $(P<0.05)$ increased vegetative tree growth over the course of five growing seasons relative to the no treatment control (Fig. 1A). Vegetative tree growth for the $B$. juncea seed meal and $S$. alba seed meal plus mefenoxam treatments was similar to preplant soil fumigation throughout the 5year study. Growth of trees in B. napus seed meal/mefenoxam treated soils was intermediate between the control and fumigation treatments. Mefenoxam alone did not significantly $(P>0.05)$ increase tree growth relative to the control. When utilized alone, B. napus seed meal and $S$. alba seed meal significantly improved initial vegetative tree growth relative to the nontreated control, but this response was transient and not maintained beyond the first and second growing season, respectively (Fig. 1B). The growth of trees planted in B. juncea seed meal-treated soil did not differ significantly from the nontreated control at any point in this study.

Fruit yields in response to soil treatments exhibited a similar pattern to that observed for vegetative tree growth. All seed meal treatments when used in conjunction with mefenoxam resulted in cumulative fruit yields that were significantly $(P<0.05)$ greater than the nontreated control and did not differ significantly from yields attained in response to 1,3dichloropropene-chloropicrin soil fumigation (Fig. 2). When used alone, among seed meal treatments, only $S$. alba seed meal significantly $(P=0.038)$ increased cumulative fruit yield relative to the control, but yields were significantly lower than those attained in response to preplant soil fumigation, B. juncea seed meal/ mefenoxam, or $S$. alba/mefenoxam soil treatments. The postplant mefenoxam treatment alone did not improve Gala/M26 cumulative fruit yields relative to the control $(P=0.311)$.

Relative growth and yield achieved in response to soil treatments at the $\mathrm{CV}$ orchard, in general, were associated with suppression of the pathogen complex which incites replant disease at this site. As 
anticipated based upon previous trials, $B$. napus seed meal and $S$. alba seed meal amendments significantly $(P<0.001)$ increased populations of Pythium spp. in orchard soils prior to planting, from 165 $\mathrm{CFU} \mathrm{g} \mathrm{g}^{-1}$ soil to $>4,500 \mathrm{CFU} \mathrm{g}^{-1}$ soil. All other treatments, including the nontreated control, had low Pythium soil populations which were not significantly different and induced root infection rates ranging from 0 to $6 \%$ of the roots sampled (data not shown). Relative to the control, infection rates were significantly higher in $B$. napus $(13 \% ; P=0.015)$ and $S$. alba $(12 \% ; P=$ $0.024)$ seed meal-amended soils. Given the absence of detectable root infection by Pythium spp. of trees established in $B$. juncea seed meal-amended soil (data not shown), the increase in vegetative growth attained in response to the postplant me-
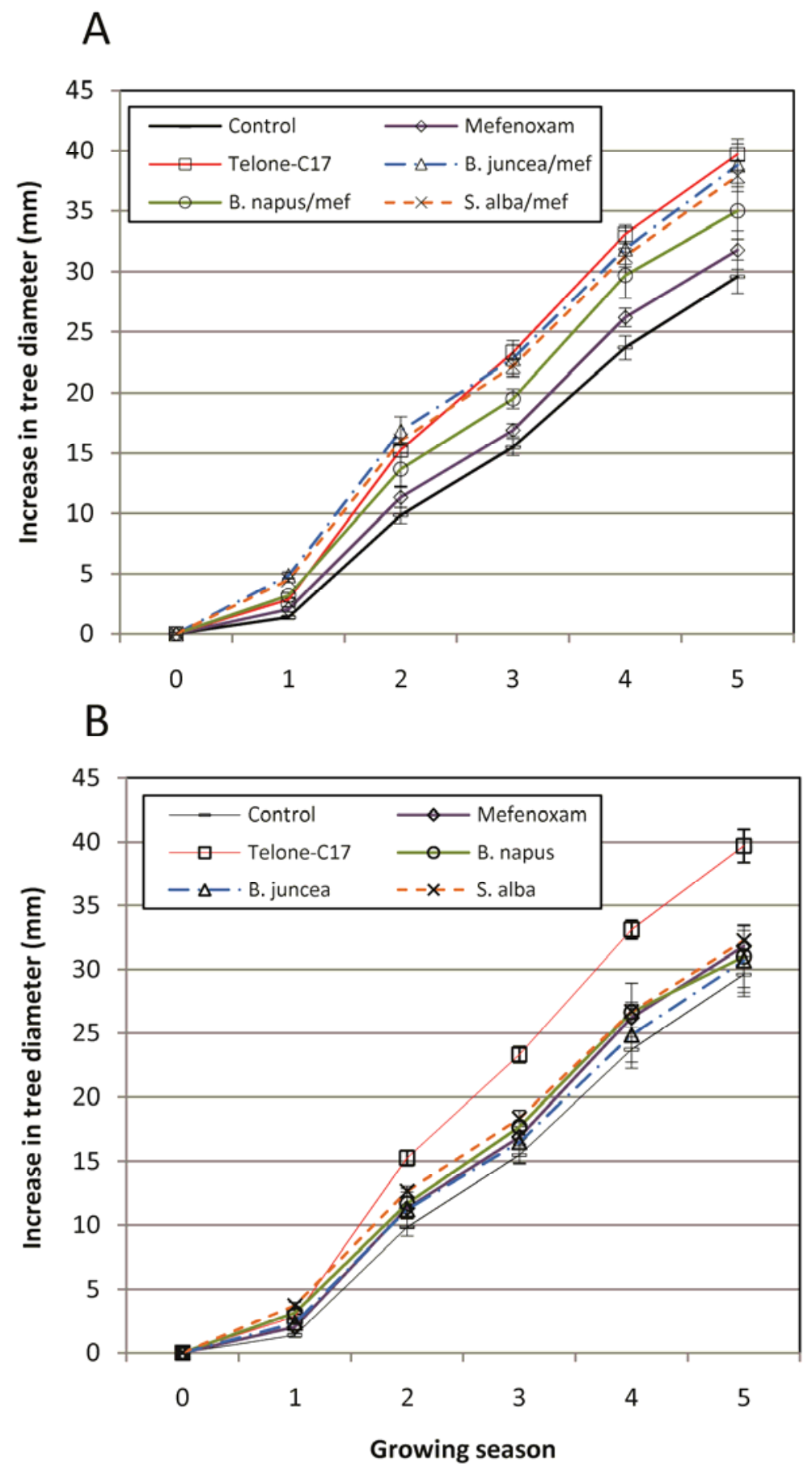

Fig. 1. Effect of brassicaceous seed meal soil amendment A, with or $\mathbf{B}$, without a postplant mefenoxam soil drench on increase in trunk diameter measured $0.7 \mathrm{~m}$ above soil surface of Gala/M26 apple over five growing seasons at the Columbia View research orchard, Orondo, WA. Measurements were obtained at planting in May 2005 (0) and thereafter in October of each year (1 to 5). Values are means of five replicates each consisting of 10 trees. Treatment abbreviations are as follows: TeloneC17 = 1,3-dichloropropene-chloropicrin; B. napus = Brassica napus; B. juncea = Brassica juncea $;$ S. alba = Sinapis alba; "mef" indicates a postplant application of mefenoxam. Bars indicate standard deviation of the mean.

fenoxam soil drench was not expected. Therefore, further examination of the oomycete community resident to tree roots was explored using a DNA-based protocol. Sequence analysis of cloned amplicons obtained in reactions with DNA extracted from apple roots and oomycete specific primers indicated that all trees grown in soils treated with $B$. juncea seed meal alone were infested with Phytophthora cambivora. In contrast, Phytophthora and Pythium spp. were not detected in the clone population generated using DNA extracts from trees grown in $B$. juncea seed meal/mefenoxam treated soils. For the control, fumigation, B. napus seed meal, and $B$. napus seed meal/mefenoxam treatments, $P$. cambivora was detected in the roots of only one of five sampled trees. Phytophthora was not represented among sequenced clones derived from root samples for either the $S$. alba seed meal or $S$. alba seed meal/mefenoxam treatments.

Percent Gala/M26 root infection by $\mathrm{Cyl}$ indrocarpon spp. differed significantly $(P$ $<0.001)$ among soil treatments. B. juncea and $S$. alba seed meal treatments with or without mefenoxam and preplant soil fumigation significantly $(P<0.05)$ reduced root infection by Cylindrocarpon spp. relative to the control (Fig. 3). Percent Cylindrocarpon root infection was similar among B. napus seed meal, B. napus $\mathrm{SM} / \mathrm{mefenoxam}$, mefenoxam, and control treatments. Rhizoctonia root infection was reduced significantly $(P<0.05)$ in response to seed meal treatments relative to the control, the sole exception in this trial being the $B$. juncea seed meal treatment (Fig. 3). Rhizoctonia root infection was lowered numerically lower in response to pre-plant soil fumigation but was not statistically different $(P=0.069)$ from the nontreated control.

SMR rootstock trial 2006. Populations of Pythium spp. were significantly higher in B. napus seed meal-amended soil relative to all other soil treatments at planting of M26 rootstock (Table 1). Inclusion of $B$. juncea seed meal in the $B$. napus seed meal amendment significantly depressed the proliferation of Pythium observed in response to $B$. napus seed meal alone. Relative Pythium densities among soil treatments were similar in the spring and autumn soil samplings. However, statistically significant $(P<0.05)$ differences between preplant 1,3-dichloropropenechloropicrin fumigation or the composite $B$. napus/B. juncea seed meal soil amendment and the control were only detected in the spring sampling. Preplant soil fumigation and B. napus/B. juncea seed meal, but not $B$. napus seed meal, amendment suppressed numbers of Pratylenchus penetrans recovered from M26 apple roots at harvest (Table 1). M26 rootstock trunk diameter was significantly $(P<0.001)$ larger for all soil treatments relative to the control (Table 1). There were no signifi- 
cant differences in shoot or root biomass among soil treatments (data not shown). In total, these data suggested that the composite seed meal formulation may have value as a strategy for control of replant disease in organic orchard systems.

SMR orchard trial 2007 to 2009. Preplant soil fumigation and the composite seed meal amendment significantly enhanced growth of Gala/M26 apple at the SMR organic orchard relative to the no treatment control (Fig. 4). After three growing seasons, increase in tree trunk diameter from the date of planting was similar for the preplant fumigation (1.61 $\mathrm{cm})$ and seed meal treatments $(1.54 \mathrm{~cm})$, and significantly $(P<0.02)$ greater than the control $(1.28 \mathrm{~cm})$. Differences in vegetative tree growth among soil treatments were associated with the level of pathogen suppression achieved. Most noteworthy was the sustained suppression of $P$. penetrans achieved in response to the composite seed meal amendment. When sampled at the end of the 2007 growing season, Gala/M26 root populations of $P$. penetrans were relatively low for all treatments, although root populations for trees in both the fumigation and seed meal treatments were significantly $(P<0.001)$ lower than that in the no treatment control (Fig. 5). By October 2009, densities of $P$. penetrans in roots of Gala/M26 grown in nontreated soil had increased from approximately 100 $\mathrm{g}^{-1}$ root to $>500 \mathrm{~g}^{-1}$ root, and were significantly $(P=0.003)$ higher than the fumigation and seed meal treatments. Infection of Gala/M26 roots by Cylindrocarpon species was significantly $(P=0.014)$ reduced from $44.2 \%$ to approximately $25 \%$ in both the fumigated and seed meal treatments (Table 2). Seed meal amendment, but not soil fumigation, significantly $(P=0.009)$ reduced Pythium spp. soil populations relative to the control. Although Pythium root infection was not significantly different among soil treatments at either the 2007 or 2009 sampling, the trend in both years was for lower infection rates in the seed meal and fumigation treatments. The majority (58\%) of Pythium isolates recovered from apple roots at this site were identified as $P$. ultimum var. ultimum, with additional species including $P$. sylvaticum (16\%), P. irregulare $(11 \%)$, and $P$. rostratifingens (5\%). Rhizoctonia root infection was not detected among root samples collected in 2007, but Rhizoctonia spp. were recovered from all treatments in the 2009 root samples. Percent Rhizoctonia root infection was $<5 \%$ for all treatments, and there were no significant differences among soil treatments. All Rhizoctonia spp. isolates recovered from roots of apple at this site were binucleate species belonging to anastomosis group (AG)-G or AG-I.

\section{DISCUSSION}

Development of nonfumigant alternatives for the management of apple replant disease is considered a daunting task due to the complexity of organisms that can incite the disease and the supposed variability in the causal biological consortia among orchard sites. While nonfumigant methods are sought for conventional systems, the need is perhaps even more vital to organic production systems which continue to employ soil fumigation for the control of replant disease due to the absence of effective alternatives. Development of an effective nonfumigant method for control of replant disease compatible with organic standards will be of signifi- cant value, as it will preempt the need to recertify replanted orchard ground after fumigation.

The system employed in this and previous studies has centered on the use of preplant brassicaceous seed meal amendments for the control of apple replant disease in conventional and organic orchard management systems. The current trial supported the findings of a previous trial (19) whereby $B$. napus seed meal amendment in conjunction with a postplant metalaxyl soil drench effectively promoted growth and yield of apple, but only when lesion

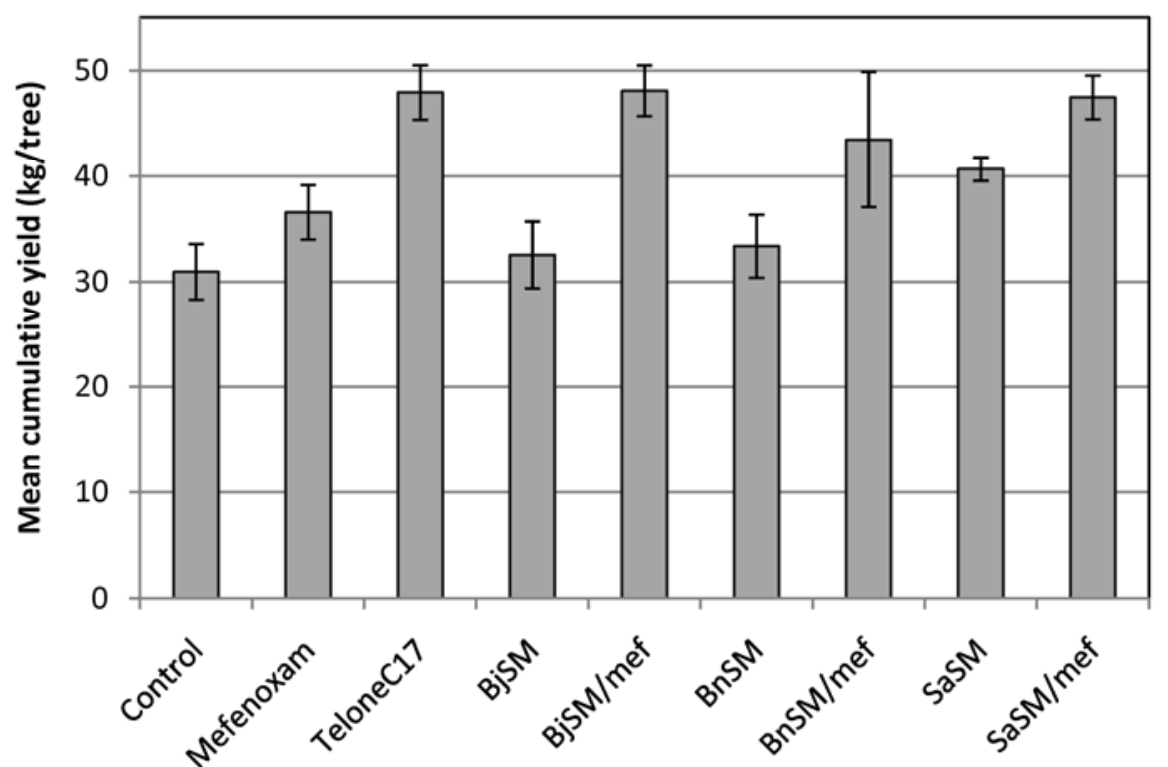

Fig. 2. Effect of soil treatments on cumulative fruit yields (2006 to 2009) from Gala/M26 apple planted at the Columbia View research orchard Orondo, WA. Treatment abbreviations are as follows: $\mathrm{BjSM}=$ Brassica juncea seed meal; $\mathrm{BnSM}=$ Brassica napus seed meal; $\mathrm{SaSM}=$ Sinapis alba seed meal; TeloneC17 = 1,3-dichloropropene-chloropicrin. Seed meal designations followed by "mef" indicate a postplant application of mefenoxam. Values are means of five replicates each consisting of 10 trees. Bars indicate standard deviation of the mean.

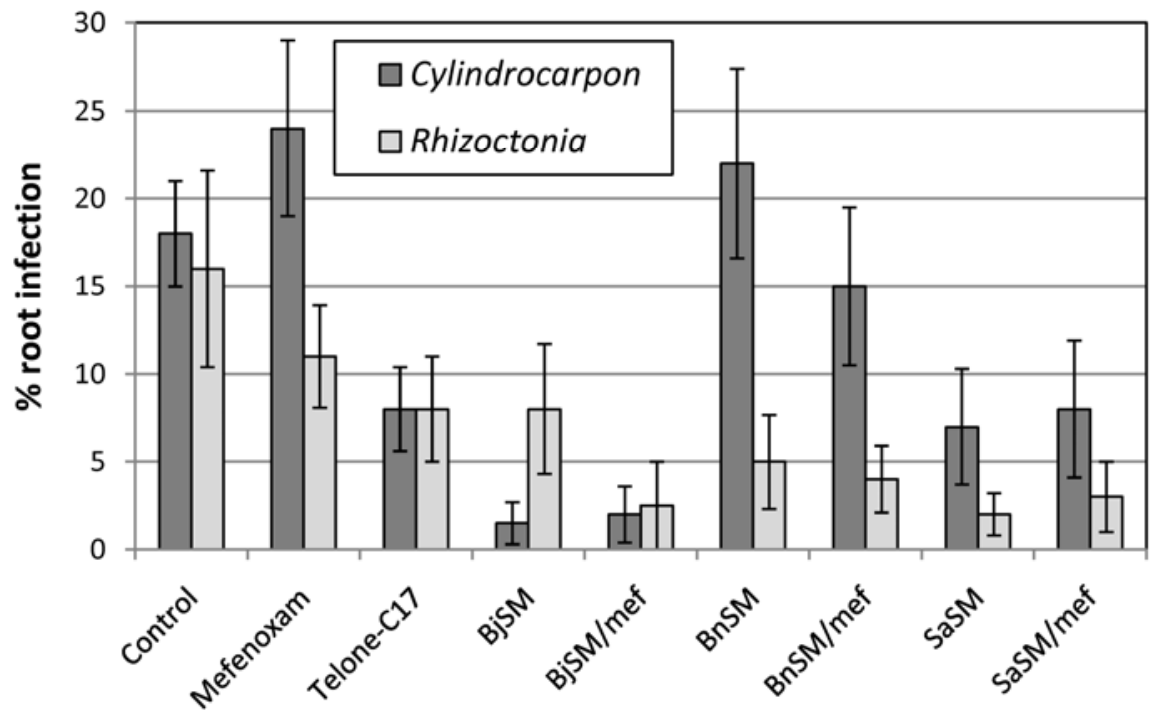

Fig. 3. Effect of soil treatments on infection of Gala/M26 apple roots by Cylindrocarpon and Rhizoctonia spp. at the Columbia View orchard trial, October 2005. Treatment abbreviations are as follows: $\mathrm{BjSM}=$ Brassica juncea seed meal; BnSM = Brassica napus seed meal; $\mathrm{SaSM}=$ Sinapis alba seed meal; TeloneC17 = 1,3-dichloropropene-chloropicrin. Seed meal designations followed by "mef" indicate a postplant application of mefenoxam. Bars indicate standard deviation of the mean. 
Table 1. Effect of preplant soil treatments on populations of Pythium recovered from soil, populations of Pratylenchus penetrans (number per gram of root) recovered from apple roots, and trunk growth of M26 rootstock at the Stormy Mountain Ranch orchard, Chelan, WA

\begin{tabular}{|c|c|c|c|c|}
\hline Treatment & $\begin{array}{c}\text { Pythium CFU g-1 } \\
\text { soil (May 2006) }\end{array}$ & $\begin{array}{l}\text { Pythium CFU g-1 } \\
\text { soil (Oct. 2006) }\end{array}$ & $\begin{array}{c}\text { \# Pratylenchus } \\
\text { penetrans } \mathrm{g}^{-1} \text { root } \\
\text { (Oct. 2006) }\end{array}$ & $\begin{array}{l}\text { Increase in } \\
\text { diameter } \\
(\mathrm{mm})\end{array}$ \\
\hline Control & $550 \mathrm{~b}^{\mathrm{z}}$ & $604 \mathrm{a}$ & $114 \mathrm{~b}$ & $1.22 \mathrm{a}$ \\
\hline $\begin{array}{l}\text { 1,3-dichloropropene- } \\
\text { chloropicrin }\end{array}$ & $135 \mathrm{a}$ & $350 \mathrm{a}$ & $59 \mathrm{a}$ & $1.75 \mathrm{~b}$ \\
\hline $\begin{array}{l}\text { Brassica napus } \\
\text { seed meal }\end{array}$ & $3890 \mathrm{c}$ & $3917 \mathrm{~b}$ & $109 \mathrm{~b}$ & $1.67 \mathrm{~b}$ \\
\hline $\begin{array}{l}\text { B. napus/B. juncea } \\
\text { seed meal }\end{array}$ & $129 \mathrm{a}$ & $300 \mathrm{a}$ & $42 \mathrm{a}$ & $1.70 \mathrm{~b}$ \\
\hline$P=$ & $<0.001$ & $<0.001$ & 0.015 & $<0.001$ \\
\hline
\end{tabular}

${ }^{\mathrm{z}}$ Means in the same column followed by the same letter are not significantly different at $P>0.05$.
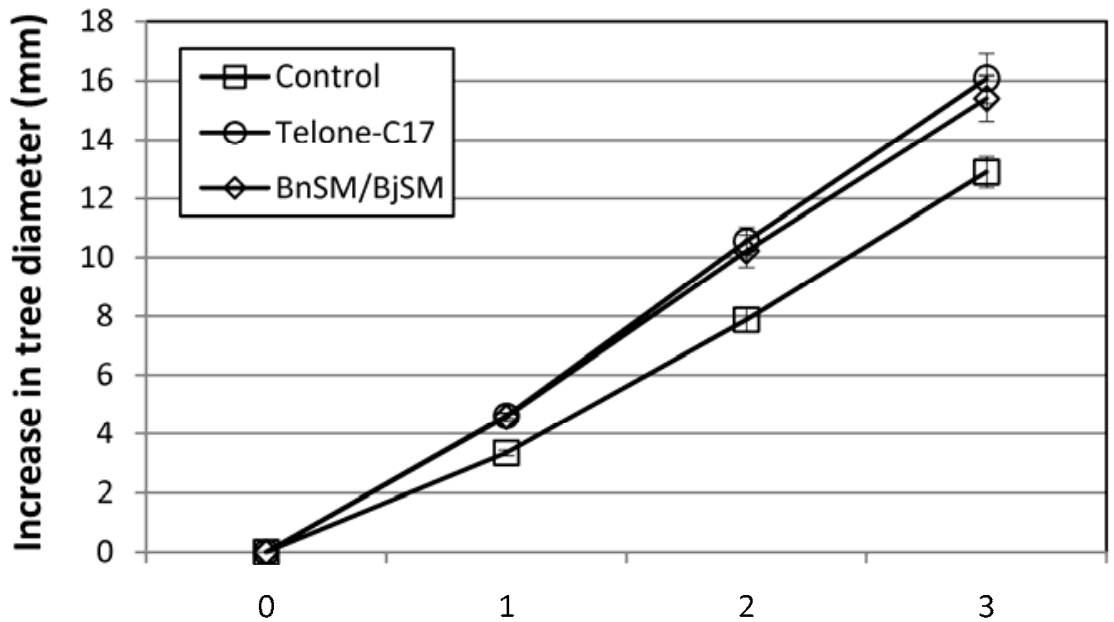

Growing season

Fig. 4. Effect of soil treatments on increase in trunk diameter measured $0.7 \mathrm{~m}$ above soil surface of Gala/M26 apple over three growing seasons at the Stormy Mountain Ranch commercial organic orchard, Chelan, WA. Measurements were obtained at planting in May 2007 (0) and thereafter in October of each year (1 to 3). Treatment abbreviations are as follows: BnSM/BjSM = Composite 1:1 formulation of Brassica juncea and B. napus seed meal; TeloneC17 = 1,3-dichloropropene-chloropicrin. Values are means of six replicates each consisting of 12 trees. Bars indicate standard deviation of the mean.

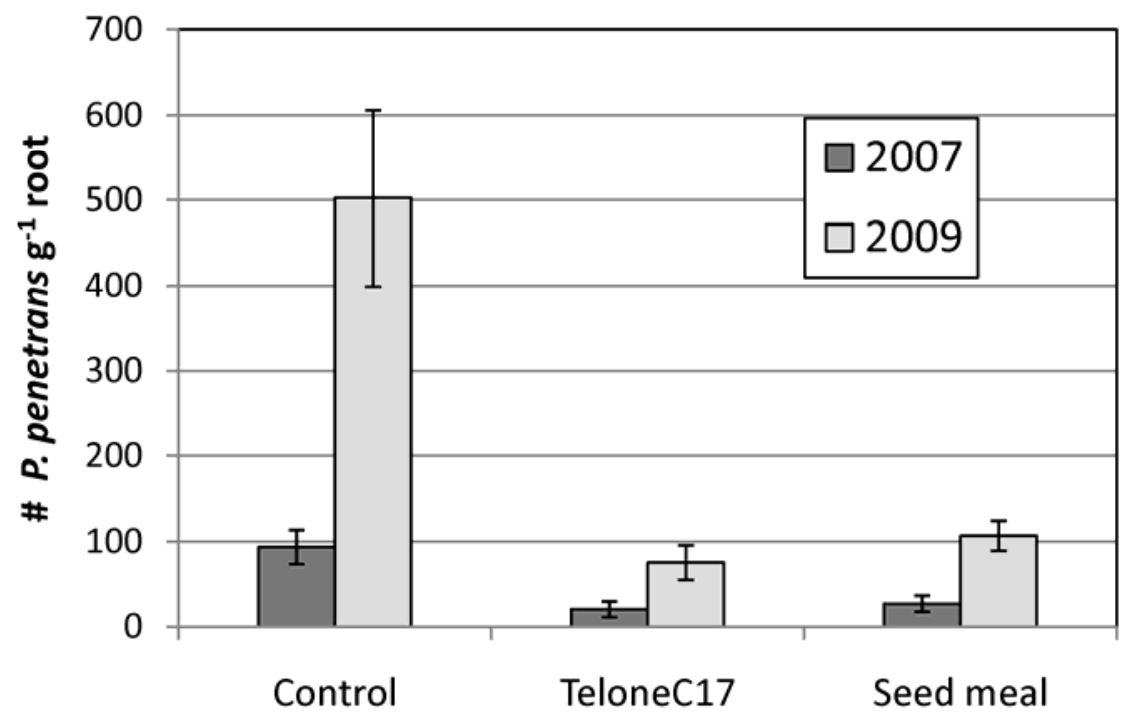

Fig. 5. Effect of soil treatments on population of Pratylenchus penetrans recovered from roots of Gala/M26, one (2007) and three (2009) growing seasons after application at the Stormy Mountain Ranch commercial organic orchard, Chelan, WA. Seed meal treatment consisted of a 1:1 formulation of Brassica napus and B. juncea seed meal. TeloneC17 = 1,3-dichloropropene-chloropicrin. Bars indicate standard deviation of the mean. nematode did not contribute significantly to replant disease, as is the case at $\mathrm{CV}$ orchard. Given the available data from controlled environment studies concerning the biological activity of the seed meals studied $(16,17)$, there existed an expectation that $B$. juncea seed meal soil amendment would independently provide effective control of replant disease. This assumption was based upon the observation that $B$. juncea seed meal amendment does not stimulate Pythium $(16,17)$, and therefore would negate the need for postplant application of mefenoxam, which is required for effective replant disease control with the Pythium-stimulating B. napus seed meal $(7,19)$. Tree performance in soils amended with $B$. juncea seed meal or $S$. alba seed meal receiving a postplant mefenoxam soil drench was equivalent to trees established in fumigated soils and superior to that attained in response to the $B$. napus seed meal/mefenoxam treatment. However, when $B$. juncea seed meal was utilized independently at the CV orchard, Gala/M26 growth and yield were no different from those attained in the no treatment control. These findings indicated that an oomycete pathogen was responsible for the poor growth of trees in response to the independent $B$. juncea seed meal treatment.

Failure of the $B$. juncea seed meal to provide disease control when used alone at the $\mathrm{CV}$ orchard was primarily due to the emergence of Phytophthora cambivora as the dominant pathogen isolated from apple roots, as other elements of the causal biological complex were effectively controlled. The contribution of $P$. cambivora to disease development at this site was unexpected, as $P$. cactorum previously was identified as the most prevalent Phytophthora species in soils from the CV orchard (14), and Phytophthora spp. were not detected using conventional root plating methods in the current trial. The contribution of $P$. cambivora to growth and yield suppression was only detected through comparative analysis of tree growth in B. juncea-amended soils with and without postplant mefenoxam and molecular characterization of the oomycete population resident to roots of trees grown in these respective soils.

Initial data from the $\mathrm{CV}$ orchard trial indicated that the seed meal/mefenoxam treatments employed in the study could provide control of apple replant disease. However, it was evident that none of the brassicaceous seed meal amendments would be compatible with organic production systems, as in each instance a postplant mefenoxam application was required for effective disease control. Therefore, subsequent studies were conducted at the SMR orchard to evaluate a composite amendment consisting of $B$. juncea and $B$. napus seed meals. This seed meal formulation was selected due to the spectrum of 
biological activity possessed by the individual seed meals when used as a soil amendment. For example, B. napus seed meal amendment elevates, but $B$. juncea seed meal effectively suppresses resident populations of Pythium spp. (16,17). The converse appeared to be true with respect to the activity of Phytophthora spp. in CV soil amended with the respective seed meals; infection of Gala/M26 roots by $P$. cambivora was elevated in $B$. juncea seed meal but not $B$. napus seed meal treated soils.

The composite seed meal amendment improved vegetative growth of Gala/M26 apple in a pattern equivalent to that attained in response to 1,3-dichloropropenechloropicrin preplant soil fumigation. Enhanced tree growth response was consistent with suppression of the pathogen complex associated with replant disease at this site. Soil fumigation and seed meal amendment had nearly indistinguishable effects on soil populations or apple root infection by Cylindrocarpon, Pythium, and Pratylenchus penetrans. A notable exception was the superior suppression of $P y$ thium spp. soil populations in response to seed meal amendment which was observed in the October 2007 soil sampling of the SMR orchard field trial. The composite seed meal provided prolonged suppression of lesion nematode populations to a level equivalent to that attained through preplant soil fumigation. This is of consequence as the previous failure of $B$. napus seed meal/mefenoxam treatment to control replant disease at one orchard site (19) was attributed to the rapid reinfestation of seed meal-amended soil, and associated root infestation, by Pratylenchus penetrans. These results indicate that the composite seed meal treatment when used independently can be effective for replant disease control and are of significance, as at present effective control measures compatible with organic production standards do not exist.

The M26 apple rootstock used in these and previous trials is among the most susceptible to the various members of the pathogen complex that incites replant disease (17). This fact and the positive results obtained in these trials suggest that there exists significant capacity to improve upon performance of a replant disease control system that utilizes brassicaceous seed meal amendments. Rootstocks tolerant or resistant to particular elements of the pathogen complex have been identified $(4,9,17)$, and controlled environment studies indicate that the capacity of seed meal amendments to provide disease control can function in a rootstock-dependent manner (17). For instance, a significant rootstock $\times$ seed meal interaction was detected in the ability of B. napus seed meal and $S$. alba seed meal amendments to suppress root populations of $P$. penetrans. When utilized in concert with M7, M26, MM106, or MM111 rootstocks, these seed meals did not provide lesion nematode control, but effective suppression was attained with the Geneva series rootstocks G11 and G30, which overall sustain lower populations of this plant parasitic nematode (17).

Replant disease continues to be among the most important challenges to the effective re-establishment of apple orchards on sites previously planted to this tree fruit crop. Although preplant soil fumigation is an effective means to control replant diseases $(8,10)$, development of alternative methods continues to be warranted due to the environmental issues associated with use of these chemistries, uncertainty concerning their long-term availability, the desire among growers for environmentally sustainable disease control methods, and the need for such alternatives in organic production systems. The series of studies conducted with brassicaceous seed meals indicates that these materials can be effective as a central component of a nonfumigant strategy for the control of apple replant disease. In organic systems, a seed meal formulation is likely to be required to effectively suppress the multiple biological components contributing to replant disease. In conventional production systems, a diversity of brassicaceous seed meals may be suitable for use with the postplant mefenoxam treatment in orchard soils where $P$. penetrans does not contribute significantly to disease development. Conversely, on sites possessing high lesion nematode densities, among the three seed meals tested, B. juncea seed meal should be a constituent of the formulation, as its

Table 2. Effect of preplant soil treatments on soil populations of Pythium and recovery (percentage of root samples analyzed) of Pythium spp. and Cylindrocarpon destructans from the roots of Gala/M26 apple trees at the Stormy Mountain Ranch orchard, Chelan, WA

\begin{tabular}{lcccc}
\hline & $\begin{array}{c}\text { Cylindrocarpon } \\
\text { root infection (\%) } \\
\text { Oct. 2009 }\end{array}$ & $\begin{array}{c}\text { Pythium soil } \\
\text { population } \\
\text { (CFU g-1 soil) } \\
\text { Oct. 2007 }\end{array}$ & $\begin{array}{c}\text { Pythium root } \\
\text { infection (\%) } \\
\text { Oct. 2007 }\end{array}$ & $\begin{array}{c}\text { Pythium root } \\
\text { infection (\%) } \\
\text { Oct. 2009 }\end{array}$ \\
\hline $\begin{array}{l}\text { Treatment } \\
\begin{array}{l}\text { 1,3-dichloropropene- } \\
\text { chloropicrin }\end{array}\end{array}$ & $44.2 \mathrm{~b}^{\mathrm{z}}$ & $533 \mathrm{~b}$ & $15.4 \mathrm{a}$ & $9.2 \mathrm{a}$ \\
$\begin{array}{c}\text { Brassica napus/ } \\
\text { B. juncea seed meal }\end{array}$ & $27.5 \mathrm{a}$ & $425 \mathrm{~b}$ & $10.0 \mathrm{a}$ & $6.9 \mathrm{a}$ \\
$P=$ & $22.5 \mathrm{a}$ & $167 \mathrm{a}$ & $9.2 \mathrm{a}$ & $6.7 \mathrm{a}$ \\
\hline
\end{tabular}

${ }^{\mathrm{z}}$ Means in the same column followed by the same letter are not significantly different at $P<0.05$. prolonged nematicidal activity will be required to attain effective replant disease control $(17,19)$.

\section{LITERATURE CITED}

1. Brown, J., Davis, J. B., Erickson, D. A., Brown, A. P., and Seip, L. 1997. Registration of 'IdaGold' mustard. Crop Sci. 38:541.

2. Brown, J., Davis, J. B., Erickson, D. A., Seip, L., and Gosselin, T. 2004. Registration of 'Pacific Gold' condiment yellow mustard. Crop Sci. 44:2271-2272.

3. Brown, J., Wysocki, D., Davis, J. B., Erickson, D. A., Seip, L., Ott, S., and Gosselin, T. 2004 Registration of 'Athena' winter rapeseed. Crop Sci. 45:800-801.

4. Browne, G. T., and Mircetich, S. M. 1993 Relative resistance of thirteen apple rootstocks to three species of Phytophthora. Phytopathology 83:744-749.

5. Catská, V., and Taube, B. H. 1994. Biological control of replant problems. Acta Hortic 363:115-120.

6. Cohen, M. F., and Mazzola, M. 2006. Resident bacteria, nitric oxide emission and particle size modulate the effect of Brassica napus seed meal on disease incited by Rhizoctonia solani and Pythium spp. Plant Soil 286:75-86.

7. Cohen, M. F., Yamasaki, H., and Mazzola, M. 2005. Brassica napus seed meal soil amendment modifies microbial community structure, nitric oxide production and incidence of Rhizoctonia root rot. Soil Biol. Biochem. 37:1215-1227.

8. Covey, R., Benson, N. R., and Haglund, W. A. 1979. Effects of soil fumigation on the apple replant disease in Washington USA. Phytopathology 69:684-686.

9. Isutsa, D. K., and Merwin, I. A. 2000. Malus germplasm varies in resistance or tolerance to apple replant disease in a mixture of New York orchard soils. HortScience 35:262-268.

10. Mai, W. F., and Abawi, G. S. 1981. Controlling replant disease of pome and stone fruits in northeastern United States by preplant fumigation. Plant Dis. 65:859-864.

11. Man in 't Veld, W. A., de Cock, A. W. A. M., Ilieva, E., and Lévesque, C. A. 2002. Gene flow analysis of Phytophthora porri reveals a new species: Phytophthora brassicae sp. nov. Eur. J. Plant Pathol. 108:51-62.

12. Manici, L. M., Lazzeri, L., and Palmieri, S. J. 1997. In vitro fungitoxic activity of some glucosinolates and their enzyme-derived products toward plant pathogenic fungi. J. Agric. Food Chem. 45:2768-2773.

13. Mazzola, M. 1997. Identification and pathogenicity of Rhizoctonia spp. isolated from apple roots and orchard soils. Phytopathology 87:582-587.

14. Mazzola, M. 1998. Elucidation of the microbial complex having a causal role in the development of apple replant disease in Washington. Phytopathology 88:930-938.

15. Mazzola, M., Andrews, P. K., Reganold, J. P. and Lévesque, C. A. 2002. Frequency, virulence, and metalaxyl sensitivity of Pythium spp. isolated from apple roots under conventional and organic production systems. Plant Dis. 86:669-675.

16. Mazzola, M., Brown, J., Izzo, A. D., and Cohen, M. F. 2007. Mechanism of action and efficacy of seed meal-induced pathogen suppression differ in a Brassicaceae species and time-dependent manner. Phytopathology 97:454-460.

17. Mazzola, M., Brown, J., Zhao, X., Izzo, A. D., and Fazio, G. 2009. Interaction of brassicaceous seed meal and apple rootstock on recovery of Pythium spp. and Pratylenchus penetrans from roots grown in replant soils. Plant Dis. 93:51-57.

18. Mazzola, M., Granatstein, D. M., Elfving, D. 
C., and Mullinix, K. 2001. Suppression of specific apple root pathogens by Brassica napus seed meal amendment regardless of glucosinolate content. Phytopathology 91:673-679.

19. Mazzola, M., and Mullinix, K. 2005. Comparative field efficacy of management strategies containing Brassica napus seed meal or green manure for the control of apple replant disease. Plant Dis. 89:1207-1213.

20. Moralejo, E., Clemente, A., Descals, E., Belbahri, L., Calmin, G., Lefort, F., Spies, C. F. J., and McLeod, A. 2008. Pythium recalcitrans sp. nov. revealed by multigene phylogenetic analysis. Mycologia 100:296-305.

21. Moran, R. E., and Schupp, J. R. 2003. Preplant monoammonium phosphate fertilizer and compost affects the growth of newly planted 'Macoun' apple trees. HortScience 38:32-35.

22. Moran, R. E., and Schupp, J. R. 2005. Preplant monoammonium phosphate fertilizer and compost affects the growth and yield of newlyplanted 'Macoun' apple trees. HortScience
40:1854-1856.

23. Slykhuis, J. T., and Li, T. S. C. 1985. Response of apple seedlings to biocides and phosphate fertilizers in orchard soils in British Columbia. Can. J. Plant Pathol. 7:294-301.

24. Tambong, J. T., de Cock, A. W. A. M., Tinker, N. A., and Lévesque, C. A. 2006. Oligonucleotidearray for identification and detection of $P y$ thium species. Appl. Environ. Microbiol. 72: 2691-2706.

25. Tewoldemedhin, Y. T., Lamprecht, S. C., McLeod, A., and Mazzola, M. 2006. Characterization of Rhizoctonia spp. recovered from crop plants used in rotational cropping systems in the Western Cape province of South Africa. Plant Dis. 90:1399-1406.

26. Traquiar, J. A. 1984. Etiology and control of orchard replant problems: A review. Can. J. Plant Pathol. 6:54-62.

27. Utkhede, R. S., and Smith, E. M. 1994. Development of biological control of apple replant disease. Acta Hortic. 363:129-134.
28. Van Schoor, L., Denman, S., and Cook, N. C. 2009. Characterisation of apple replant disease under South African conditions and potential biological management strategies. Sci. Hortic. 119:153-162.

29. White, T. J., Bruns, T., Lee, S., and Taylor, J. 1990. Amplification and direct sequencing of fungal ribosomal RNA genes for phylogenetics. Pages 315-324 in: PCR Protocols: A Guide to Methods and Applications. M. A. Innis, D. H. Gelfand, J. J. Sninsky, and T. J. White, eds Academic Press, San Diego, CA.

30. Willett, M., Smith, T. J., Peterson, A. B., Hinman, H., Stevens, R. G., Ley, T., Tvergyak, P. Williams, K. M., Maib, K. M., and Watson, J. W. 1994. Growing profitable apple orchards in replant sites: An interdisciplinary team approach in Washington state. HortTechnology $4: 175-181$

31. Wilson, S., Andrews, P., and Nair, T. S. 2004 Non-fumigant management of apple replant disease. Sci. Hortic. 102:221-231. 